\title{
CLINICAL AND BIOCHEMICAL CHANGES DURING EXCHANGE TRANSFUSION
}

BY

\author{
JAMES W. FARQUHAR and HYLTON SMITH \\ From the Department of Child Life and Health, University of Edinburgh, and the Edinburgh Central Hospital \\ Group Biochemical Laboratory
}

(RECEIVED FOR PUBLICATION AUGUST 26, 1957)

The development of exchange transfusion has greatly altered the prognosis of haemolytic disease of the newborn and the procedure is now accepted as being essential in cases of any severity. It is carried out wherever the criteria for operation are fulfilled and by operators of varying skill and experience. The difficulties associated with blood transfusion have received increasing attention in recent years, and its employment is beset with problems not only of cytology and serology but of microbiology, biochemistry, allergy, dynamics, religion and race. Some of these are greatly increased by the volume of blood used in exchange transfusion. Considering that the infant may be perfused with stored blood of altered chemistry in quantities of up to three times his own blood volume, it is surprising perhaps that it can be done at all. Hazards such as sepsis, air embolism, portal-vein thrombosis and perforation of the umbilical vein have been described, but are fortunately uncommon. Circulatory overloading is an ever-present danger in the profoundly anaemic infant, and it may be precipitated by conducting the exchange transfusion too rapidly. Deterioration and even death, however, may occur in infants whose pre-operative condition gave rise to no concern. Such clinical deterioration was observed in $40 \%$ of the cases transfused by Walker and Neligan (1955), and it did not appear to be related in any simple way to the baby's initial condition, to birth weight, to the technical difficulties encountered or to the rate of exchange. Moreover, Walker (1955) was led to believe, from inquiries received by him, that unexpected death was commoner over the United Kingdom than he had previously thought. Signs of clinical disturbance which had been observed by one of us (J. W. F.) during exchange transfusions at the Simpson Memorial Maternity Pavilion, Edinburgh, between 1948 and 1953, prompted us to undertake a joint study of a series of infants during operation.

\section{Plan of Investigation}

In the belief that analysis of serum taken during exchange transfusion would reflect the ability of the newborn infant suffering from erythroblastosis foetalis to maintain a normal serum electrolyte picture, electrolyte balance with reference to calcium and potassium ions has been evaluated.

\section{Methods}

Clinical. The technique of exchange transfusion was essentially that described by Farquhar and Lewis (1949). A careful clinical record was kept during the transfusion. This included recording the volume of blood exchanged, heart rate, and the occurrence of clinical incident. The exchange was carried out slowly, and if the patient was not tolerating the procedure the apparatus was flushed with saline and the infant rested for 5-15 minutes. As many as three or four rest periods were necessary for readjustment in some of the more seriously disturbed babies.

Specimens of blood were collected at regular intervals during transfusion. In the first series of cases studied blood was collected at intervals immediately before the administration of calcium gluconate. In the second series blood was collected at intervals immediately before and after the administration of calcium gluconate. In the event of any abnormal incident occurring during transfusion, specimens of blood were collected immediately. During specimen collection, contamination of blood samples with the contents of the polythene catheter was avoided by the following procedure. A few millilitres of the infant's blood was sucked into the syringe and rejected into the waste bucket. By this means any residual donor blood was removed from the polythene catheter. The actual blood specimen was then withdrawn and placed in a centrifuge tube. Specimens were centrifuged soon after clot retraction, and the sera were stored in the refrigerator until analysis.

Analytical. Sodium and potassium were determined by means of the flame photometer; protein by the micro-Kjeldahl procedure (King, 1951); total calcium by the method of Sobel and Sobel (1939), with the modification that the serum was ashed prior to oxalate precipita- 
tion in order to eliminate citrate; citric acid by a method devised by one of us (H.S.), the principle depending on the oxidation of citrate to acetone with vanadate, and the subsequent distillation of the liberated acetone into an alkaline solution of salicylaldehyde, forming a coloured complex which was measured colorimetrically.

Simultaneous electrocardiography would have been of much value, but unfortunately no suitable machine was available.

\section{Patterns of Clinical Disturbance Observed}

A quite unexpected near-fatality observed during exchange transfusion in 1953 finally provoked these observations.

A mature female infant of $8 \mathrm{lb} .6 \mathrm{oz}$. birth weight, second of a family, had a cord haemoglobin of $17 \cdot 4 \mathrm{~g}$. per $100 \mathrm{ml}$., a cord serum bilirubin of $3 \mathrm{mg}$. per $100 \mathrm{ml}$., and a strongly positive Coombs test. There was no splenomegaly and the liver was judged to be normal. Influenced only by the bilirubin level, it was decided to carry out an exchange transfusion. No trouble was anticipated. Aliquots of $10 \mathrm{ml}$. of blood were exchanged at an average time interval of one minute. Calcium gluconate $0.1 \mathrm{~g}$. was injected at intervals of $100 \mathrm{ml}$. The operation proceeded smoothly until $430 \mathrm{ml}$. had been exchanged, when the infant suddenly collapsed and became pale and unresponsive. The heart rate increased from 132 to 152 beats per minute. Calcium was given without effect. Glucose $20 \%$ solution was given intravenously quite empirically in a dosage of $6 \mathrm{ml}$. The baby appeared to improve, but on resumption of the exchange she collapsed again. Glucose was given once more with less convincing effect. The transfusion was then continued much more cautiously and in negative balance to a total of $740 \mathrm{ml}$.

Of the 19 infants studied, one died during transfusion. Six others showed some clinically recognizable disturbance at some stage of the procedure. The remaining 12 infants were normal throughout. Different patterns of clinical disturbance were observed, and a description of these is essential to the further understanding of the investigation.

Distal Cyanosis. Two babies produced an alarming clinical picture which, probably as a result of modification in technique, was not observed in subsequent transfusions. In both cases ( $F$ and $R$ ) difficulty was experienced in withdrawing blood during the first $100 \mathrm{ml}$. of blood exchanged. Persistent efforts were made to overcome this by partial withdrawal and reintroduction of the catheter. In both cases the catheter tip was advanced along the umbilical vein for about $11 \mathrm{~cm}$. and repeatedly encountered some resistance, which was thought at the time to be within the portal circulation. Both babies developed a deep cyanosis of the lower half of the body, and this contrasted dramatically with the pallor of the upper half. Increased venous filling became apparent over the trunk and the veins were noted to drain superiorly. No pitting oedema of the legs was noted. The symptoms disappeared spontaneously in about half an hour. This phenomenon has been designated 'distal cyanosis'.

Retching. Three infants (B, H and J) suffered from repeated retching of mucus. This is a common observation during exchange transfusion, and because of this milder degrees have not been recorded.

Shock. Three infants (B, F and M) presented a clinical picture to which the term 'shock' has been loosely applied. These infants showed some or all of the following features in varying degree. After crying lustily initially on restraint, they became unduly quiet and pale during operation. At least one infant was so pale that the possibility of internal bleeding was considered. The babies were cool and their abdomens became distended. The latter was not due to liver enlargement. They became 'hypotonic' and unresponsive. Little change in heart rate was observed and there was no increase in venous pressure. Case B showed this clinical picture within the first $100 \mathrm{ml}$. of blood exchanged, but survived an exchange of $600 \mathrm{ml}$.

Cardiac Failure. Signs of congestive heart failure appeared in one case only $(\mathrm{J})$. This baby suffered from repeated retching during the exchange of the first $200 \mathrm{ml}$. of blood. He remained irritable, and after an exchange of $700 \mathrm{ml}$. he was beginning to show evidence of deterioration. Respiration became a little distressed and dyspnoea was obvious after $800 \mathrm{ml}$. of blood. At this stage the heart rate had increased from a resting rate of 138 to one of 164 per minute. The venous pressure in the portal circulation rose from a resting level of $7.5 \mathrm{~cm}$. to $30 \mathrm{~cm}$. The baby was a little cyanosed, the superficial veins became more obvious and the liver enlarged. Unfortunately the blood specimen taken at this point was lost, but the values found in the preceding one were coexistent with the signs of early cardiac failure.

Acute Non-fatal Collapse. One infant (R) collapsed suddenly and unexpectedly, but he fortunately recovered. He had been well until $470 \mathrm{ml}$. of blood had been exchanged. He then retched and became apnoeic and deeply cyanosed. The heart sounds were faint and the rhythm was irregular, but his condition gradually improved over a ten-minute period. This has been broadly 
termed 'acute non-fatal collapse'. Samples of this infant's blood were being taken only at intervals of $200 \mathrm{ml}$., and the nearest specimen to the incident was taken after $400 \mathrm{ml}$. of blood had been exchanged.

Death. One infant (I) died during operation. This infant was born with assistance by the breech, was limp at birth and was covered with yellow vernix. The cord haemoglobin was $9.8 \mathrm{~g}$. per $100 \mathrm{ml}$. and the serum bilirubin $3.5 \mathrm{mg}$. per $100 \mathrm{ml}$; there were very many nucleated red cells in a peripheral blood smear and the Coombs test was strongly positive. Both liver and spleen were palpably enlarged. Apart from pallor no abnormality was noted until the infant collapsed and died at $500 \mathrm{ml}$. Necropsy revealed considerable bilateral tearing of the tentorium cerebelli, and a subtentorial subdural haematoma of such size that the medulla oblongata was flattened antero-posteriorly. Considerable intraperitoneal haemorrhage was also noted. No source of bleeding was found to explain this other than some haemorrhage around the umbilical vein in the region of the anterior abdominal wall. Although no perforation was found, this seemed to be the likely source of intraperitoneal blood loss. The pathological opinion was that the subdural bleeding alone, or with the intraperitoneal haemorrhage, provided adequate reason for the baby's death.

\section{Relationship of Behaviour to Severity of Disease, Birth Weight, Volume and Speed of Exchange}

The severity of the haemolytic disease process was classified arbitrarily into three grades: mild $(+)$, moderate $(++)$ and severe $(+++)$ (Tables 1 and 2). In all cases a Coombs test was positive. The mild cases had a cord haemoglobin value greater than $14 \mathrm{~g}$. per $100 \mathrm{ml}$. and a serum bilirubin of $3 \mathrm{mg}$. per $100 \mathrm{ml}$. or less. Neither liver nor spleen was enlarged. The moderately severe cases had a cord haemoglobin value greater than $11 \cdot 2 \mathrm{~g}$. but less than $14 \mathrm{~g}$. per $100 \mathrm{ml}$. and the serum bilirubin was $3 \mathrm{mg}$. per $100 \mathrm{ml}$. or less. Some enlargement of liver and/or spleen was noted. The severe cases had a cord haemoglobin value of less than $11 \cdot 2 \mathrm{~g}$. and a serum bilirubin of more than $3 \mathrm{mg}$. per $100 \mathrm{ml}$., enlargement of liver and spleen, possibly bruising or oedema, and in one case a birth weight of less than $5 \frac{1}{2} \mathrm{lb}$.

The aim of the operation was to employ $80-120 \mathrm{ml}$. of donor blood per $\mathrm{lb}$. body weight, to use the umbilical route wherever possible and to effect the exchange fairly slowly.

There were cases where only a small volume was exchanged-for example, Case P. This infant was treated in another hospital. Attempts to employ the umbilical vein were unsuccessful and the registrar catheterized the long saphenous vein in the groin. Even here withdrawal was exceedingly difficult, and because the infant was only mildly affected the procedure was abandoned. In all cases the speed of exchange was fairly leisurely by intention, but in some it was prolonged by the technical difficulties encountered. The numbers are, of course, very small, but there is a reasonable distribution of severity. Five cases were mild, seven moderate and seven severe. If those cases which pursued a normal course are considered, four were mildly affected, three were of moderate severity and as many as five severe. Of the clinically abnormal cases, one was mildly affected, four were of moderate severity and only two severe. Of those showing the 'shock' picture, none had severe haemolytic disease. The only death occurred in the severely affected group. Only one other of this group (total seven cases) showed any abnormality, and this was limited to retching.

Regarding the speed of exchange, a total of 6.36 litres of blood was exchanged in the normal group in 1,386 minutes (excluding Cases $\mathrm{K}$ and $\mathrm{P}$ ). The average rate of exchange was $4.6 \mathrm{ml}$. per minute, In the abnormal group a total of $4 \cdot 12$ litres of blood was exchanged in 968 minutes, so that the average speed of exchange was $4.3 \mathrm{ml}$. per minute. In the cases showing no clinical disturbance, therefore, the exchange was effected a shade more quickly on the average, but the fact that in the abnormal group intentional delays followed the occurrence of incidents, and so increased the duration of operation a little, must be kept in mind.

\section{Pattern of Serum Electrolytes}

Introductory Remarks. Analytical data referring to the cases investigated are charted in Figs. 1 and 2. Fig. 1 shows the individual results obtained from six normal transfusions, while Fig. 2 shows the individual results from seven transfusions at which clinical abnormalities were observed. From reference to the appropriate figures it will be apparent that they depict only the general trend of serum electrolytes during transfusion. It will be appreciated that, since specimens were collected at intervals during transfusion, it is only at these points that electrolytes could be assessed. Fluctuation must have occurred in the periods between collection of specimens, this fluctuation being influenced by movement of electrolytes in and out of the plasma compartment and, of course, by metabolic factors. Nevertheless, if this point be borne in mind in the evaluation of the results, it is believed that the general 
pattern which emerges from this investigation adequately portrays the effect of infusion of citrated blood upon serum electrolytes.

of high citrate levels, of calcium-ion depression by citrate, of high serum potassium levels and the mutually reinforcing influences of a high potassium and a low calcium ion upon the heart. These are depicted in Figs. 3 and 4. In each graph every relevant analytical result in the series is included and marked by a symbol which denotes the clinical state of the patient at the time when the sample was taken. In Fig. 3 the coexisting citrate and calcium-ion levels are entered against each other. If high citrate levels per se were responsible for clinical abnormality, then the symbols denoting abnormal behaviour should be across the top of the graph. If clinical abnormality were the result of high citrate levels depressing calcium ion, however, then the abnormal cases should be at the top of the graph and towards the left. The upper part of the graph does not in fact contain the abnormal cases, nor do they lie predominantly to the left of the picture. The one death does lie in the top left-hand corner, but otherwise there is reasonable dispersal of the abnormal symbols among those which imply normal be-

The Group as a Whole. From the outset of the investigation attention was focused on the relationship of four biochemical situations to the clinical behaviour of the baby. These were: the influence haviour when the specimen was taken. In Fig. 4 the serum potassium levels were plotted against the coexisting levels of calcium ion. If hyperpotassaemia were responsible, then the abnormal cases 
should lie across the top of the picture, whereas if depression of calcium ion were responsible, then they should lie to the left of the picture. If the offending biochemical upset were coexisting hyperpotassaemia and calcium-ion depression, then the abnormal cases should lie in the top left-hand quadrant. Apart from the important exception that the only death did in fact represent the highest serum potassium level at the lowest calcium-ion level, the other abnormal symbols are scattered across the
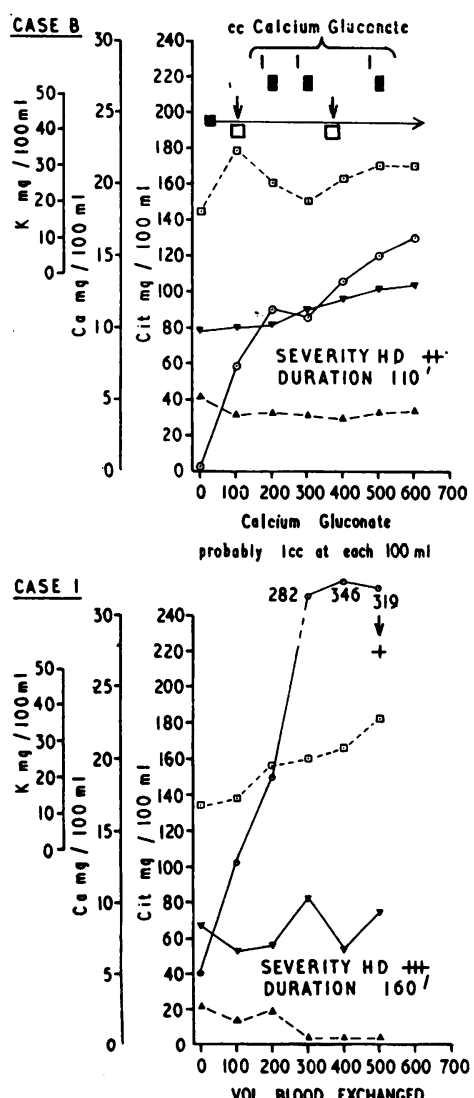
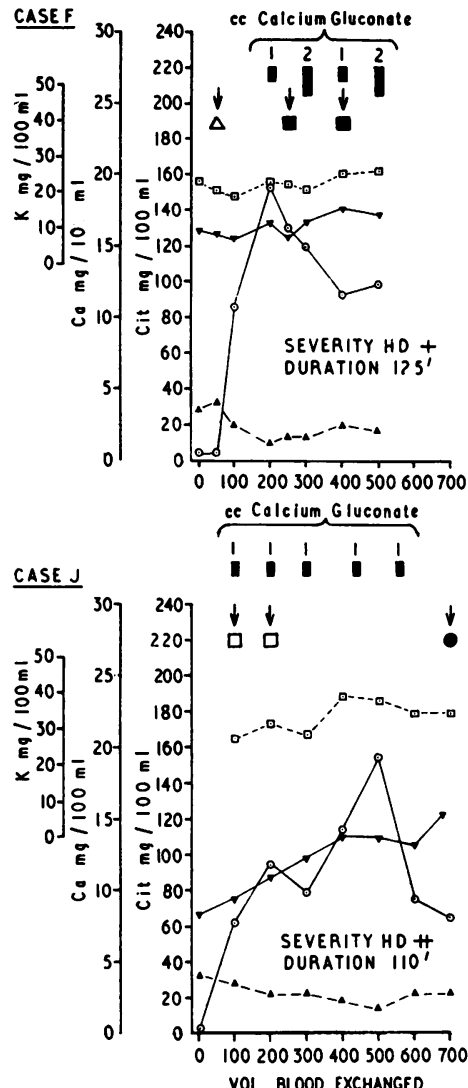
VOL BLOOD EXCHANGED

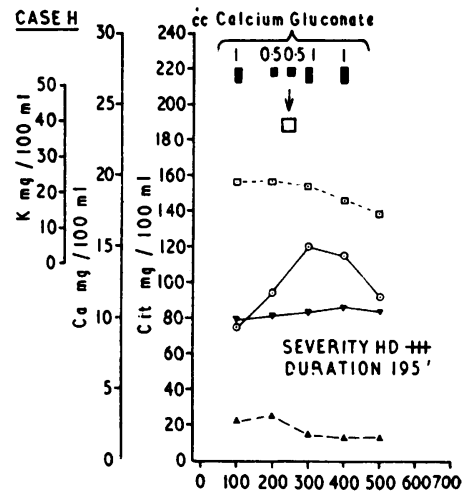

ce Calcium Giuconate

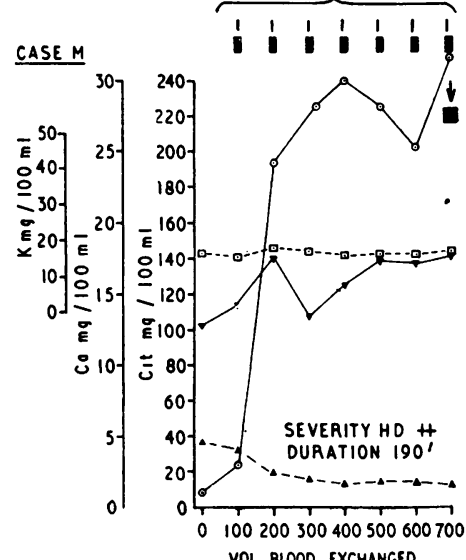
VOL. BLOOD EXCHANGED

ec Calcium Gluconate

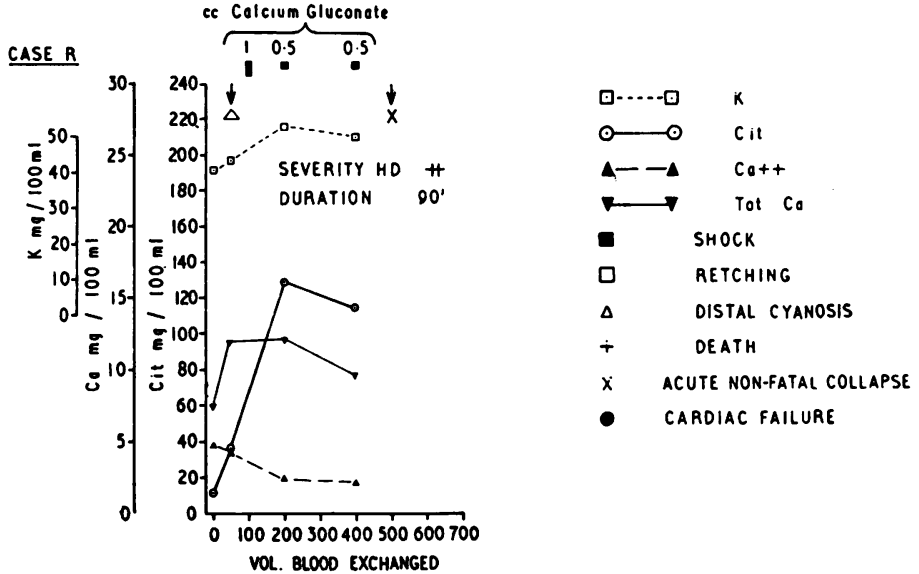

Fig. 2.-Serial serum electrolyte levels during seven abnormal exchange transfusions. 
picture and fairly evenly disposed among the normal cases. From these two pictures it is possible to state that, with the exception of the fatal case, there was no relationship in this series of cases between the coexisting biochemical values and the clinical behaviour at the moment of taking the specimen.

It was apparent that a pattern of serum electrolytes during transfusion emerged from this investigation, this pattern being common to all infants whether or not clinical incident was observed. In summary, there appeared to be an increase in total calcium and citrate, a decrease in active calcium ion, and either no change or an increase in serum potassium. Several conclusions have been drawn from these results.

Citrate and Calcium. Great excess of citrate was found in the serum during exchange transfusion,

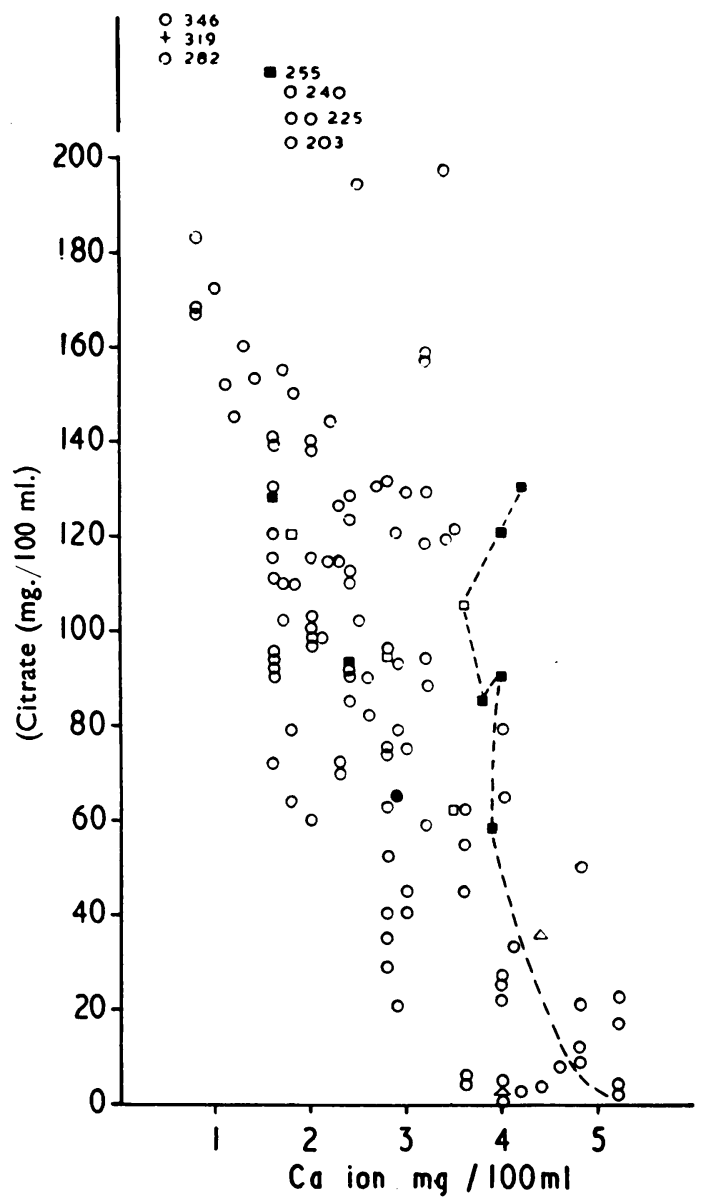

Fig. 3-Clinical behaviour during exchange transfusion related to plasma values of citrate and calcium ion. and if, in fact, the formation of calcium citrate in vivo were dependent only upon chemical kinetic factors, then all available calcium ion in the plasma of these infants, except for the small amount liberated in the primary dissociation, should have been combined as calcium citrate. That this situation did not exist was apparent from the clinical state of the infants. The physiological environment, then, must be more complex than experiments in vitro would suggest, although all the calcium supplied in the form of calcium gluconate appeared to be inactivated immediately after injection (Fig. 5), if it can be presumed that calcium gluconate is completely ionized. The results are illustrated in Fig. 5. The absence of the classical manifestations of hypocalcaemia during transfusion even though subsequent analysis of serum showed a profound depression of calcium-ion concentration, is difficult

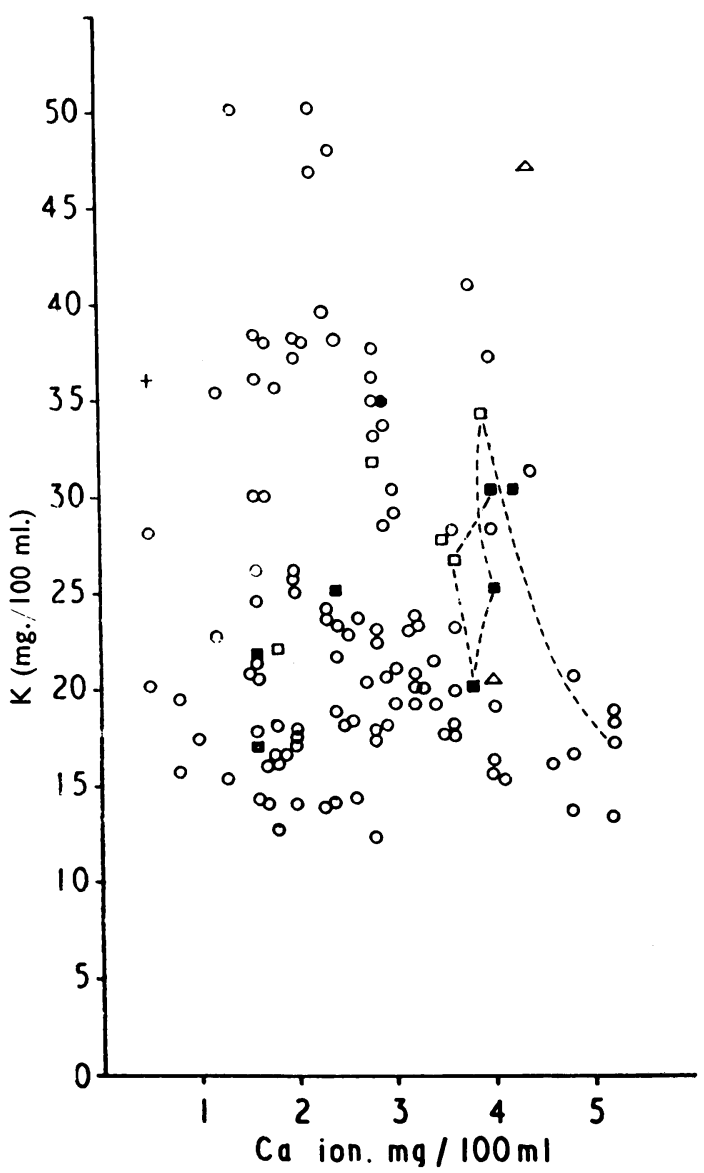

Fig. 4.-Clinical behaviour during exchange transfusion related to plasma values of potassium and calcium ion. 
to explain. Since the formation of calcium citrate is known to be a slow reaction, it is suggested that
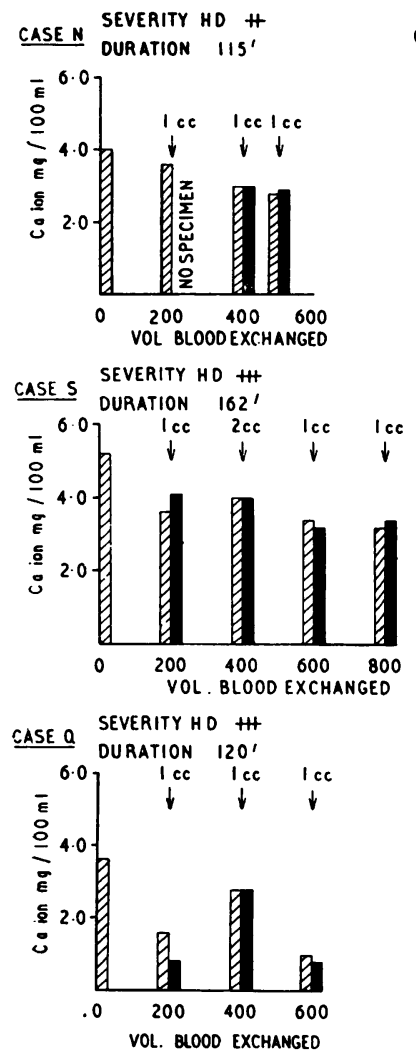

CASE O SEVERITY HO H
DURATION $114^{\prime \prime}$

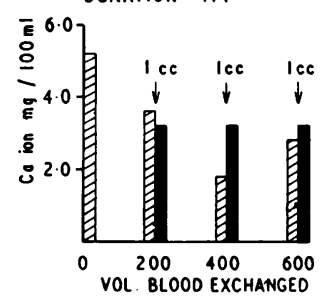

SEVERITY HO + CASEP DURATION Nol recorded

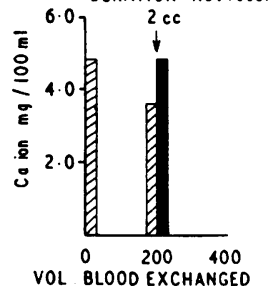

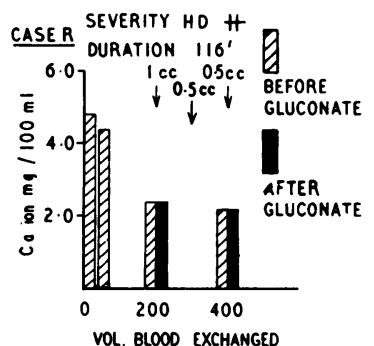

Fig. 5.-Effect of calcium gluconate on serum calcium-ion concentration.

complex formation may have been incomplete during transfusion, but on storage of the serum in the absence of active metabolic factors the reaction between citrate and calcium ions was able to reach completion.

It is claimed that during exchange transfusion the rate of transfusion is the most important factor in the development of hypercitraemia. Table I shows the infusion rate of citrate in this series, and it is apparent that the safety rate recommended by Mollison (1951) was commonly exceeded. There did not appear to be any correlation between the hypercitraemia and the citrate infusion rate, and it is considered significant that hypercitraemia of equal severity developed in both the clinically normal and abnormal groups. All infants showed considerable ability to 'metabolize' infused citrate, even in the presence of alleged hepatocellular immaturity.

It has been postulated that a high serum citrate level in the resting state is indicative of hepatocellular dysfunction. Hypercitraemia was commonly observed in the pre-transfusion state in this investigation. Natelson et al., (1948) quoted the normal range of serum citrate as 1.5 to $6.0 \mathrm{mg}$. per $100 \mathrm{ml}$., with a mean value of $3.8 \mathrm{mg}$. per $100 \mathrm{ml}$., and in this series the range was 1.4 to $40.0 \mathrm{mg}$. per $100 \mathrm{ml}$, with a mean value of $12.6 \mathrm{mg}$. per $100 \mathrm{ml}$. The fatal case had a resting serum citrate level of $40.0 \mathrm{mg}$. per $100 \mathrm{ml}$., yet post-mortem examination revealed no gross hepatocellular damage. Furthermore, liver enlargement was not a common feature in any of the other cases, but this does not exclude the possibility of a 'metabolic' immaturity existing. Confirmatory evidence of high resting citrate values has been provided by the low level of resting serum calcium ion observed in this series.

TABLE 1

TABLE RELATING RATE OF TRANSFUSION, RATE OF CITRATE INFUSION AND INCIDENCE OF CLINICAL ABNORMALITY

\begin{tabular}{|c|c|c|c|c|c|c|}
\hline Case & $\begin{array}{l}\text { Severity of } \\
\text { Haemolytic } \\
\text { Disease }\end{array}$ & $\begin{array}{l}\text { Birth } \\
\text { Weight } \\
\text { (kg.) }\end{array}$ & $\begin{array}{l}\text { Volume of Blood } \\
\text { Exchanged } \\
\text { (ml.) }\end{array}$ & $\begin{array}{l}\text { Time taken } \\
\text { for Exchange } \\
\text { (minutes) }\end{array}$ & $\begin{array}{c}\text { Citrate Infused } \\
\text { (mg./kg./hr.) }\end{array}$ & Incident \\
\hline $\begin{array}{l}\mathbf{A} \\
\mathbf{B} \\
\mathbf{C} \\
\mathbf{D} \\
\mathbf{E} \\
\mathbf{F} \\
\mathbf{G} \\
\mathbf{H} \\
\mathbf{I} \\
\mathbf{J} \\
\mathbf{K} \\
\mathbf{L} \\
\mathbf{M} \\
\mathbf{N} \\
\mathbf{O} \\
\mathbf{P} \\
\mathbf{Q} \\
\mathbf{R} \\
\mathbf{S}\end{array}$ & $\begin{array}{l}+ \\
++ \\
++ \\
++ \\
+++ \\
+ \\
+ \\
+++ \\
+++ \\
++ \\
++ \\
++ \\
++ \\
++ \\
+++ \\
++ \\
++ \\
++ \\
+++\end{array}$ & $\begin{array}{l}3 \cdot 2 \\
2 \cdot 9 \\
3 \cdot 3 \\
3 \cdot 2 \\
2 \cdot 5 \\
2 \cdot 6 \\
3 \cdot 5 \\
2 \cdot 3 \\
2 \cdot 7 \\
3 \cdot 3 \\
3 \cdot 2 \\
3 \cdot 0 \\
2 \cdot 7 \\
2 \cdot 6 \\
3 \cdot 8 \\
3 \cdot 2 \\
3 \cdot 6 \\
3 \cdot 8\end{array}$ & $\begin{array}{l}700 \\
600 \\
700 \\
700 \\
500 \\
500 \\
700 \\
500 \\
500 \\
850 \\
300 \\
600 \\
700 \\
500 \\
600 \\
200 \\
560 \\
470 \\
800\end{array}$ & $\begin{array}{c}129 \\
107 \\
162 \\
128 \\
150 \\
125 \\
156 \\
195 \\
160 \\
110 \\
240 \\
150 \\
190 \\
115 \\
114 \\
\text { Not recorded } \\
120 \\
81 \\
162\end{array}$ & $\begin{array}{l}286 \\
397 \\
202 \\
400 \\
356 \\
-293 \\
242 \\
218 \\
542 \\
80 \\
385 \\
240 \\
404 \\
302 \\
303 \\
298 \\
334\end{array}$ & $\begin{array}{l}\text { Shock, retching } \\
\text { Distal cyanosis } \\
\text { Retching - } \\
\text { Death } \\
\text { Retching, heart failure } \\
\text { Shock - } \\
\begin{array}{l}\text { Distal cyanosis, acute collapse } \\
\text { - }\end{array}\end{array}$ \\
\hline
\end{tabular}


Potassium. Variations in serum potassium during exchange transfusion were unpredictable. Hill (1954) quoted the normal range of serum potassium in the newborn infant as 17.5 to $21.1 \mathrm{mg}$. per $100 \mathrm{ml}$. In this series the normal pre-transfusion

TABLE 2

ANALYSIS OF CASES ACCORDING TO SEVERITY OF HAEMOLYTIC DISEASE

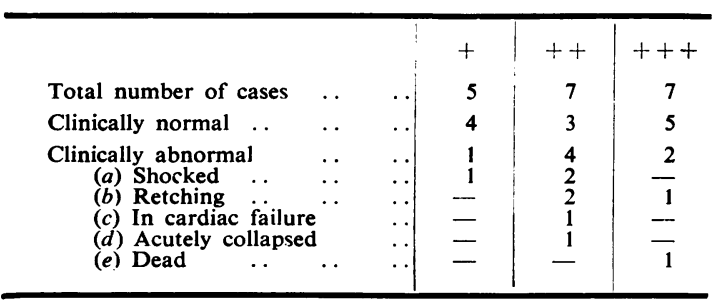

range was 13.3 to $40.0 \mathrm{mg}$. per $100 \mathrm{ml}$. Table 3 shows that five infants $(F, G, K, N, R)$ had pretransfusion serum potassium levels above normal, and in these instances either no change or a rise accompanied the transfusion. Of those infants who had a normal pre-transfusion serum potassium level, five $(B, D, I, J, L)$ developed a hyperpotassaemia during transfusion. All these infants were transfused with donor blood with a plasma potassium content of over $30.0 \mathrm{mg}$. per $100 \mathrm{ml}$. Except in the fatal case, however, the hyperpotassaemia was not relatable to any particular clinical abnormality, since the phenomenon was observed in both clinically normal and abnormal infants. Furthermore, two infants classified as clinically abnormal $(\mathrm{H}, \mathrm{M})$ had a normal serum potassium level throughout transfusion. One point is worthy of note: the plasma potassium level of the donor blood used in the fatal case was $110 \mathrm{mg}$. per $100 \mathrm{ml}$., and at death coexisting high potassium and low calcium-ion concentrations were recorded. Whether the high potassium level influenced the onset of cardiac failure could not be ascertained, since electrolyte imbalance was not considered to be the cause of death.

\section{Summary of Biochemical Changes in Abnormal Cases}

Fig. 2 illustrates serum electrolyte changes during exchange transfusion in the abnormal cases.

Distal Cyanosis. This was not associated with any particular electrolyte pattern. Symptoms appeared early in the exchange, and at a time when serum citrate was beginning to rise and serumcalcium ion to fall. Both infants had a pre-transfusion hyperpotassaemia, which persisted throughout transfusion.

Retching (Cases B, H, J). This was associated with a hyperpotassaemia, a rising serum citrate level, and a serum calcium ion which was by no means unduly low when compared with other apparently normal transfusions.

Shock (Cases B, F, M). In Case B, shock appeared before any marked change in either serum citrate or calcium ion, but hyperpotassaemia was present after only $100 \mathrm{ml}$. of blood had been exchanged, and therefore coexisted with the appearance of clinical signs of shock. Case F presented

TABLE 3

CHANGES IN SERUM POTASSIUM DURING EXCHANGE TRANSFUSION

\begin{tabular}{|c|c|c|c|c|c|c|c|c|}
\hline \multirow{3}{*}{ Case } & \multicolumn{8}{|c|}{ Volume of Blood Exchanged (ml.) } \\
\hline & 0 & 100 & 200 & 300 & 400 & 500 & 600 & 700 \\
\hline & \multicolumn{8}{|c|}{ Serum Potassium (mg. per 100 anl.) } \\
\hline $\begin{array}{l}\mathbf{A} \\
\mathbf{B} \\
\mathbf{C} \\
\mathbf{D} \\
\mathbf{E} \\
\mathbf{F} \\
\mathbf{G} \\
\mathbf{H} \\
\mathbf{I} \\
\mathbf{J} \\
\mathbf{K} \\
\mathbf{L} \\
\mathbf{M} \\
\mathbf{N} \\
\mathbf{O} \\
\mathbf{P} \\
\mathbf{Q} \\
\mathbf{R} \\
\mathbf{S}\end{array}$ & $\begin{array}{l}16 \cdot 2 \\
17 \cdot 0 \\
13 \cdot 3 \\
20 \cdot 5 \\
16 \cdot 1 \\
23 \cdot 1 \\
37 \cdot 0 \\
\overline{12 \cdot 4} \\
\overline{31 \cdot 0} \\
\overline{16 \cdot 5} \\
28 \cdot 0 \\
18 \cdot 7 \\
17 \cdot 7 \\
19 \cdot 9 \\
40 \cdot 8 \\
18 \cdot 0\end{array}$ & $\begin{array}{c}20 \cdot 5 \\
34 \cdot 0 \\
13 \cdot 6 \\
20 \cdot 5 \\
16 \cdot 1 \\
18 \cdot 8 \\
37 \cdot 5 \\
23 \cdot 0 \\
14 \cdot 0 \\
27 \cdot 7 \\
36 \cdot 0 \\
20 \cdot 0 \\
15 \cdot 7 \\
- \\
- \\
- \\
-\end{array}$ & $\begin{array}{l}-\overline{25 \cdot 0} \\
19 \cdot 0 \\
21 \cdot 4 \\
13 \cdot 8 \\
22 \cdot 7 \\
38 \cdot 0 \\
23 \cdot 1 \\
18 \cdot 0 \\
31 \cdot 6 \\
30 \cdot 0 \\
24 \cdot 5 \\
18 \cdot 2 \\
28 \cdot 0 \\
18 \cdot 1 \\
24 \cdot 3 \\
21 \cdot 8 \\
53 \cdot 2 \\
17 \cdot 6\end{array}$ & $\begin{array}{c}20 \cdot 8 \\
20 \cdot 0 \\
14 \cdot 3 \\
23 \cdot 2 \\
17 \cdot 4 \\
20 \cdot 6 \\
38 \cdot 4 \\
22 \cdot 0 \\
20.0 \\
28 \cdot 3 \\
50 \cdot 0 \\
23 \cdot 5 \\
17.0 \\
= \\
- \\
- \\
-\end{array}$ & $\begin{array}{l}20 \cdot 4 \\
26 \cdot 5 \\
14 \cdot 0 \\
38 \cdot 0 \\
17 \cdot 5 \\
25 \cdot 1 \\
38 \cdot 2 \\
17 \cdot 8 \\
28 \cdot 0 \\
39 \cdot 5 \\
\overline{18 \cdot 0} \\
16 \cdot 0 \\
29 \cdot 0 \\
21 \cdot 7 \\
\overline{17 \cdot} \cdot 8 \\
50 \cdot 1 \\
24 \cdot 8\end{array}$ & $\begin{array}{l}22 \cdot 7 \\
30 \cdot 0 \\
14 \cdot 0 \\
35 \cdot 4 \\
15 \cdot 4 \\
26 \cdot 0 \\
36 \cdot 2 \\
14 \cdot 4 \\
36 \cdot 0 \\
38 \cdot 0 \\
18 \cdot 0 \\
16 \cdot 5 \\
= \\
- \\
- \\
-\end{array}$ & $\begin{array}{c}24 \cdot 0 \\
30 \cdot 0 \\
12 \cdot 7 \\
26 \cdot 0 \\
\overline{-} \\
35 \cdot 7 \\
\overline{-} \\
34 \cdot 8 \\
\overline{-} \\
16 \cdot 5 \\
33 \cdot 0 \\
22 \cdot 4 \\
\overline{17 \cdot 3} \\
\overline{21 \cdot 4}\end{array}$ & $\begin{array}{l}25 \cdot 7 \\
\overline{17 \cdot 7} \\
24 \cdot 4 \\
\overline{-} \\
3 \overline{37 \cdot 0} \\
\overline{-} \\
34 \cdot 8 \\
\overline{-} \\
\overline{17 \cdot 1} \\
\overline{-} \\
\overline{-} \\
\overline{-} \\
19 \cdot 0\end{array}$ \\
\hline $\begin{array}{l}\text { Mean } \\
\text { value }\end{array}$ & $21 \cdot 6$ & $22 \cdot 9$ & $24 \cdot 9$ & $24 \cdot 3$ & $26 \cdot 0$ & $25 \cdot 2$ & $26 \cdot 7$ & $25 \cdot 0$ \\
\hline
\end{tabular}


only a mild hyperpotassaemia. Signs of shock appeared towards the end of the transfusion in Case M. At this time the serum citrate level had suddenly increased to $250 \mathrm{mg}$. per $100 \mathrm{ml}$., but serum potassium was within the normal range. Serum calcium-ion level was apparently uninfluenced by the sudden change in citrate, remaining, as it had done throughout the transfusion, at about $2 \mathrm{mg}$. per $100 \mathrm{ml}$.

Cardiac Failure (Case J). Heart failure appeared at a point in the transfusion when the serum electrolytes were beginning to return towards normal. The citrate level had fallen substantially, total calcium had reached a peak of $15 \mathrm{mg}$. per $100 \mathrm{ml}$., calcium ion had risen by $1.0 \mathrm{mg}$. per $100 \mathrm{ml}$., and serum potassium had fallen by $5 \mathrm{mg}$. per $100 \mathrm{ml}$. to a level of $30 \mathrm{mg}$. per $100 \mathrm{ml}$.

Acute Non-fatal Collapse (Case R). The infant collapsed after $500 \mathrm{ml}$. of blood had been exchanged, and the nearest sample of blood to this incident, taken at $400 \mathrm{ml}$., indicated a profound hyperpotassaemia although the serum citrate level was falling and the serum calcium ion was relatively stable at $2 \mathrm{mg}$. per $100 \mathrm{ml}$. It is significant that the bottle of donor blood had been changed after $400 \mathrm{ml}$. had been transfused, and the plasma potassium concentrations in the two bottles were $85.4 \mathrm{mg}$. and $52.8 \mathrm{mg}$. per $100 \mathrm{ml}$. respectively. The plasma potassium value after the exchange of $400 \mathrm{ml}$. of blood, although high, was actually a little lower than it had been earlier, and a further reduction might have been expected by the time of the clinical incident, in view of the lower plasma potassium content of the second bottle.

Death (Case I). In the fatal case, serum citrate had reached by far the highest level in the series, yet death took place when the citrate level was beginning to decrease. Serum calcium-ion concentration was not measurable, nor had it been for some time before death. At the time of death serum potassium had reached a peak value of $36 \mathrm{mg}$. per $100 \mathrm{ml}$. Thus there existed a profound hypocalcaemia and hyperpotassaemia.

Hyperpotassaemia. This was the only constant feature of the abnormal cases, and it was severe in the cases of cardiac failure, acute non-fatal collapse and death. Three apparently normal infants (D, G, L), however, exhibited hyperpotassaemia of similar magnitude.

Conclusion. It is believed that none of the clinical incidents was due entirely to electrolytic imbalance, since similar biochemical changes were common to all the infants of the series. Serum electrolytes reflect the total electrolyte pattern to some degree, but clinical abnormality need not necessarily be the result of a sudden change in plasma electrolytes. Rather it may be due to prolonged exposure of the intracellular environment to a gradually changing extracellular environment. Considered from this point of view, a study of serum electrolytes throughout a transfusion is more important than the assessment of electrolytes at any particular instant in a transfusion. Critical evaluation of the results of this investigation has failed to show a correlation between electrolytic imbalance and clinical abnormality during transfusion, but there is no doubt that all infants undergoing exchange transfusion are exposed to an abnormal biochemical state over a prolonged period.

\section{GENERAL DISCUSSION}

\section{Citrate}

Hypercitraemia. The possible importance of rising levels of plasma citrate in the production of symptoms during infusion of citrated blood was emphasized by Wexler et al. (1949) and Ames et al. (1950). The level of citrate was found to rise to a figure 10 to 30 times greater than the pre-transfusion value. This was accompanied by a decrease in plasma calcium-ion concentration. Prolongation of the Q-T interval on ECG tracings was recorded by Ames et al. (1950). Although the latter could be attributed to the depression of calcium-ion concentration by citrate, no constant relationship existed between the plasma citrate concentration and the ECG change. Furthermore, the Q-T interval could return to normal in the presence of continued high levels of citrate. These studies were made on convalescent infants. Plasma citrate, total calcium and total protein were determined, and plasma calcium-ion concentration was assessed indirectly by employing the normogram of McLean and Hastings (1935). Several of the babies became irritable during the infusion; their skins were pale and mottled, and a normal skin temperature was not restored by the use of blankets alone. One infant collapsed suddenly and responded only to prolonged resuscitative measures. Another was found dead during transfusion. The authors considered that these acute disturbances were almost certainly the result of acute lowering of plasma calcium-ion level. Critical study of the case records, however, shows no convincing evidence for such a belief and reveals the presence of other factors predisposing to complication. They believed that the absence of reactions 
in the majority of cases might be explained on the basis of the existence of forces capable of counteracting the calcium-ion-lowering effect of citrate. However, they provide no explanation of why these two less fortunate individuals should have been deficient in this homoeostatic mechanism. More recently Bunker et al. (1955) have shown, in a series of 130 adults who received moderate to large volumes of citrated blood, that many patients developed hypercitraemia, and theoretically calciumion concentration in the plasma ought to have been seriously depressed. More marked elevation of plasma citrate occurred when transfusion was extremely rapid, prolonged or repeated. Higher levels also occurred where the liver was damaged, and this may be important in the newborn infant with or without haemolytic disease.

The present investigation has demonstrated conclusively that a great increase in serum citrate occurs during the infusion of citrated blood, and it is important to consider the facts which influence this phenomenon. The acid-citrate-dextrose mixture used as an anticoagulant in this country has been criticized and praised for many years. When it was first instituted the dangers of citrate were emphasized, but until the technique of replacement transfusion and massive blood transfusion became common, little attention was focused upon the possibility of citrate intoxication in medical practice. In the infants in this series, amounts of citrate ranging from 738 to $3,413 \mathrm{mg}$. were infused into a plasma compartment of less than $200 \mathrm{ml}$. average volume, so that accumulation of citrate under these circumstances could be dangerous. It is believed that citrate in stored donor blood is confined essentially to the plasma. Thus, if the recommended ratio of volume of anticoagulant to blood is strictly adhered to, then the plasma citrate content of the donor blood should be about $600 \mathrm{mg}$. per $100 \mathrm{ml}$. It will be appreciated that any marked deviation from the standard technique may result in significant changes in the plasma citrate. Ames particularly emphasized this point when describing an alleged case of citrate intoxication following the infusion of plasma containing $1,536 \mathrm{mg}$. of citrate per $100 \mathrm{ml}$. With this in mind Walker and Neligan (1955) recommend the use of packed cells in exchange transfusion.

Speed of Citrate Infusion. Although the plasma citrate level in the donor blood is the first consideration, the rate at which it is infused is obviously important. It is desirable that the rate of transfusion be adjusted so that the homoeostatic mechanisms controlling citrate are able to deal with the citrate as fast as it is being infused. Mollison (1956) stipulates a maximum rate of $260 \mathrm{mg}$. of citrate per $\mathrm{kg}$. of body weight per hour, but Wexler et al. (1949) and Walker et al. (1955) freely admit to exceeding this rate without clinical incident. In the present series similar conditions prevailed. Nakasone et al. (1954) performed an interesting experiment in which citrate solutions of varying strengths were infused into dogs and the response of cardiac muscle was measured by ECG tracings. They suggested that it was not the actual level of citrate in the perfusate which was the factor precipitating cardiac changes, but rather the cumulative dose of citrate in the animal's body. In other words, hypocalcaemia was induced after the infusion of a critical amount of citrate, whether this was attained over a short period by the infusion of a solution containing a high concentration of citrate or after a longer period with a solution containing less citrate. For this reason the slower the rate of transfusion the less severe the hypercitraemia which will develop. It is suggested that the clinical incidents in this series were not related to the infusion rate of citrate. Reference to Table 1 will show that the safety rate was often exceeded in cases which appeared normal throughout transfusion, yet in other abnormal cases the infusion rate was below the recommended safety rate.

Metabolism of Citrate. It should be borne in mind that reports describing rapid metabolic breakdown of citrate during the infusion of citrated blood are based on observations of plasma citrate concentration during a period when rapid diffusion out of the plasma compartment is occurring. Transfer of citrate to other compartments of body water would account, at least in part, for the disappearance of exogenous citrate out of the plasma water. The average amount of citrate contained in $100 \mathrm{ml}$. of citrated donor blood is $370 \mathrm{mg}$. Assuming that no transfer occurred out of the plasma compartment into interstitial water, then the amount of this citrate which would be retained after the exchange of $100 \mathrm{ml}$. of blood by the technique employed in this investigation would be about $320 \mathrm{mg}$. In practice, however, a proportion of this would be transferred to interstitial water, and, assuming even distribution throughout the extracellular water, about a seven-fold reduction in the theoretical maximum plasma concentration could be expected. The actual level in the plasma would depend on the degree of transfer of the citrate at the time of collection of the specimen, but it should be within the range of $46-320 \mathrm{mg}$. per $100 \mathrm{ml}$. Thus the levels recorded in this series indicate that a considerable portion of infused citrate migrated 
out of the plasma compartment after each $100 \mathrm{ml}$. of blood exchanged. Increased intracellular metabolism of citrate was likely to occur under the stimulus of the infusion of citrate. The exact rate of oxidation of citrate in the human being is unknown, but toxic effects appear to depend on dosage and rate of administration. Most tissues contain a specified citric-acid dehydrogenase, the liver and renal parenchyma being the most active sites of metabolism (Thunberg, 1953; Mårtensson, 1940). Wexler observed delayed removal of citrate from plasma in one fatal case which showed gross liver damage at necropsy, and from this evidence he postulated that delayed citrate metabolism might result from impaired liver function. In the fatal case of the present series a similar delayed removal of citrate was observed, yet post-mortem examination revealed no severe liver damage. It is quite possible that a mild degree of metabolic immaturity exists in newborn infants, especially those suffering from erythroblastosis foetalis. This would explain the resting hypercitraemia observed in some cases in this series. It can only be concluded, however, that all infants appeared to have efficient homoeostatic mechanisms for removing infused citrate from plasma.

It is suggested as a hypothesis that all the factors discussed must operate during the infusion of citrated blood. Initially the prevention of severe hypercitraemia by careful adjustment of the donor plasma citrate level and the rate of transfusion can be controlled by the operator. Presumably any infused citrate enters the plasma, and from there it is transferred to interstitial water and finally to the intracellular water, where it is metabolized. Reference to Figs. 1 and 2 will indicate the general pattern of serum citrate during transfusion. The initial dramatic rise to a level between 100 and $160 \mathrm{mg}$. per $100 \mathrm{ml}$. may represent a phase in which citrate is essentially confined to the plasma. Once mechanisms controlling transfer out of the plasma compartment become operative it is reasonable to expect a fall in the plasma citrate if the rate of transfer exceeds the rate of citrate infusion in the plasma. This has been confirmed in the present investigation. Fluctuations observed at later stages in the transfusion may reflect the efficiency of intracellular metabolic pathways. Thus a rising citrate in the presence of a constant rate of citrate infusion suggests some impairment of function (Cases I, M). Conversely, a falling serum citrate level suggests efficient metabolism, while a fluctuating citrate level may be indicative of sudden changes in the citrate intake with which the intracellular metabolic processes are unable to cope. All except two infants (I, M) were able to metabolize infused citrate very efficiently. If citrate intoxication were the causative factor in some or all of the clinical incidents in this series, then it is difficult to explain the fact that serum citrate levels of a similar magnitude did not precipitate incidents in the normal infants.

Citrate-induced Hypocalcaemia. The high serum citrate recorded in this investigation should have induced severe hypocalcaemia. The theoretical implications are that all available calcium ions in the plasma of infants undergoing transfusion should be inactivated, but the results indicate that, although significantly reduced, this reduction was not complete except in the fatal case. Two explanations are proposed. First, citrate was present in the plasma in high concentration, but there was no evidence to show whether the whole or part of it was present in an active ionic form. In fact an inactive molecule, possibly bound to protein, may have existed. Such complexes are known to exist in the case of protein and glucose and the lipoproteins. Under such circumstances only ionized citrate would be available for reaction with calcium and other cations. Secondly, the formation of calcium citrate is not an instantaneous reaction, and this might explain the apparent discrepancy between the absence of clinical manifestations of tetany, even though subsequent analysis of serum showed a profound depression of calcium ion. During transfusion calcium citrate formation may have been incomplete, whereas on storage of the serum in the absence of enzyme action, reaction was allowed to reach completion in the presence of excess of citrate ion. Whatever the explanation, analysis revealed that complete inactivation of calcium ion in serum did not occur. There was no evidence to confirm the finding of others (Lansing and Scott, 1942) that significant mobilization of calcium ion occurred from intracellular sources, nor did it appear that the injection of calcium gluconate was effective in elevating calcium ion in serum. On clinical grounds, Walker and Neligan (1955) abandoned the use of gluconate, and they did not observe tetany in a series of 272 transfusions.

Herlitz (1942) observed active tetany in infants whose plasma calcium-ion level had fallen below $3.5 \mathrm{mg}$. per $100 \mathrm{ml}$, yet even with serum calcium-ion levels below $2.0 \mathrm{mg}$. per $100 \mathrm{ml}$., classical tetany was not seen during this investigation. The absence of clinical abnormality is not inconsistent with a reduction in calcium ion, as the factors governing neuromuscular irritability are complex, and the maintenance of a normal state of irritability may 
have been due to compensatory mechanisms. The exact means by which tetany is brought about has not yet been elucidated, but the original work of Ringer and Loeb (discussed in any standard textbook of physiology) might elucidate the problem. They postulated a delicate equilibrium between the cations of the serum, and any disturbance of this equilibrium, such as a decrease in calcium, magnesium or hydrogen ions or an increase in sodium, potassium or hydroxyl ions, causes hyperirritability of the tissues. It has been shown in this series that an increase in potassium and a decrease in calcium ion occurred in serum, thus favouring the development of neuromuscular hyperirritability.

It has been demonstrated that citrated blood is weakly acid in reaction, and the infusion of such a medium would favour the production of a metabolic acidosis. This problem is at present under investigation by Walker (personal communication, 1956), but no results have been reported to date. Increase in hydrogen-ion concentration would tend to compensate for the coexisting hypocalcaemia and hyperpotassaemia in terms of neuromuscular irritability. For example, Mudgeand Vislocky (1949) observed that the acidosis of chronic renal disease was not specifically related to a change in acid-base equilibrium, but was associated with a decrease in intracellular potassium and a rise in intracellular sodium. In this investigation perfusion of donor blood did not significantly alter the infants' sodium level in the face of a virtual replacement of their blood and a donor plasma concentration around $400 \mathrm{mg}$. per $100 \mathrm{ml}$. Since renal excretion of sodium must have been negligible during transfusion, diffusion or transfer of excess sodium out of the plasma compartment must have occurred. Is it reasonable to postulate that at least some of this sodium entered the intracellular water, possibly reflecting that some movement of potassium into the extracellular water had occurred?

\section{Potassium}

The leakage of potassium from red blood cells during storage is a well-known phenomenon (De Gowin et al., 1940), and the significance of this was emphasized by Mollison (1951). Toxic levels of potassium in blood plasma are associated with cardiac arrest, and in fact the injection of potassium citrate solution into the coronary circulation has been used experimentally to produce elective temporary cardiac arrest (Melrose et al., 1955). In the adult the transfusion of one or two pints of blood does not greatly affect the recipient's plasma potassium concentration, but the situation is different during exchange transfusion in a newborn infant, where one pint of blood is equivalent to about twice the infant's blood volume. The influence of transfusion upon serum potassium concentration in eight infants was studied by Miller et al. (1954). Hyperpotassaemia was present, particularly when the donor blood had been stored for a week or longer. No convincing proof was offered that the high potassium levels were harmful to these infants. Sudden unexplained death in two infants also prompted the investigation carried out by Campbell (1955). Hyperpotassaemia was present in three of four deaths in the series, but comparably high figures were recorded in infants who had shown no abnormality. Although the levels were potentially lethal, Campbell was unable to ascribe the deaths with certainty to hyperpotassaemia. Some success was obtained with insulin in maintaining more normal potassium levels, and the author's experience of comparative morbidity and mortality in comparable control and test groups is awaited with interest.

Serum potassium levels recorded in the present investigation indicated that $60 \%$ of infants developed a hyperpotassaemia either before or during transfusion, but these changes were common, even in the asymptomatic infants. Rise in plasma potassium level during exchange transfusion is influenced by the intake of potassium in the donor plasma, the ability of the renal mechanism to excrete excess potassium and the efficiency of intracellular 'metabolic' sites in removing potassium from the plasma. It was apparent in this investigation that the development of hyperpotassaemia was closely related to the infusion of donor blood. The incidence of hyperpotassaemia was high when the donor plasma potassium level exceeded $30.0 \mathrm{mg}$. per $100 \mathrm{ml}$. As in the case of citrate, however, the high serum potassium levels were not relatable, surprisingly, to the rate of transfusion. Thus the development of hyperpotassaemia may be due to accumulation of potassium rather than to the potassium concentration of the perfusate. In the adult renal excretion of potassium is a most important homoeostatic mechanism preventing potassium intoxication, but, since renal immaturity is an accepted phenomenon in the newborn, their ability to excrete excess potassium is doubtful. In fact the mean normal urine output in the first 24 hours is about $20 \mathrm{ml}$., so that the maintenance of a normal serum level during transfusion must depend upon mechanisms other than renal. One of these must be the transfer of potassium from the plasma to other compartments of the body water. Simple distribution within the extracellular water will result in a seven-fold decrease in the concentration of any exogenous potassium which is confined initially to the plasma. The serum potassium 
concentration per se does not necessarily reflect the state of cellular potassium, and it is not justifiable automatically to associate a high serum potassium level with a toxic accumulation of potassium in body water. In fact Tarail and Elkinton (1949) have shown that a cellular deficiency of potassium may exist in the presence of a high serum potassium level. Although this would explain the absence of potassium intoxication in the cases in this investigation with a high serum potassium level, it is difficult to imagine in infants suffering from erythroblastosis foetalis. These infants are exposed to a severe haemolytic process which starts in utero, and it is possible that in the absence of a renal homoeostatic mechanism these infants are in a state of positive potassium balance. This fact tends to be confirmed by the high incidence of resting hyperpotassaemia.

Experiments (Joseph et al., 1939; Fenn, 1939; Houssay et al., 1936; Eichelberger, 1941) have shown that the intravenous injection of soluble potassium salts results in the accumulation of potassium within the liver cells, and this process is enhanced by the simultaneous infusion of glucose solution. Presumably potassium enters the intracellular space of the hepatic cells during hepatic glycogenesis. This is suggested as a working hypothesis in the present investigation. The liver is only a temporary site, but it serves as a means of preventing potassium intoxication in the absence of renal regulating mechanisms. The liberation of potassium during glycogenolysis inevitably occurs, but at a rate which allows adequate renal excretion of potassium by the maturing renal tissue.

\section{Coexistent Hypocalcaemia and Hyperpotassaemia}

The biochemical abnormality observed in this investigation was the coexisting hyperpotassaemia and hypocalcaemia. The danger of simultaneously rising potassium and falling calcium-ion levels in the blood was described by Guest (1952). Protection of dogs against normally lethal concentrations of potassium may be provided by the intravenous injection of calcium (Winkler et al., 1939). Modification of the effects of potassium intoxication in children by the administration of calcium salts was claimed by Govan and Weiseth (1946). Latent tetany in a group of adults with coexisting hypopotassaemia and hypocalcaemia was rendered manifest by the slow intravenous infusion of potassium salts even though the final plasma potassium level did not exceed the usual normal range (Engel et al., 1949). More recently Levine et al. (1952) have claimed that hypocalcaemia may actually potentiate the electrocardiographic signs of hyperpotassaemia. None of these facts was con- firmed in this investigation. There is some suggestion that the hyperpotassaemia may have precipitated heart signs in the cases of acute non-fatal collapse, cardiac failure and death, but completely asymptomatic infants presented a hyperpotassaemia of similar magnitude. The evidence is strong in favour of profound electrolytic imbalance in the fatal case, although the actual cause of death was found to be haemorrhage. It appears that there is no association between the clinical disturbance observed during exchange transfusion and the changes which undoubtedly occur in plasma electrolytes.

\section{Other Possible Explanations of the Clinical Disturbances}

\section{Circulatory Stress}

Interference with Postnatal Readjustment of Circulation. The picture of differential cyanosis of the distal half of the body is most alarming. Only two such cases have been seen by J. W. F. and both occurred in this series. In each great difficulty had been met in withdrawing blood and much time had been spent manipulating the catheter. On the first occasion the development of some venacaval obstruction was considered, and the spontaneous resolution of the disturbance was witnessed with relief. The production of a temporary veno-arterial shunt through a patent ductus arteriosus must be considered. Increasing experimental evidence is becoming available that the ductus arteriosus does not close within a few minutes after birth. The careful studies of lambs by Dawes et al. (1954) and Born et al. (1956) at Oxford have shown that in that animal the closure takes place over hours, and is dependent on changes in oxygen tension and the release of sympathetic amines.

The occasional observation of cyanosis of the lower part of the body of newly born babies stimulated Eldridge et al. (1954) to carry out oxygen saturation studies upon arterialized capillary blood from the right hand and foot of healthy newborn human infants; 14 studies were made on 12 subjects. Of the 14 studies, eight showed significantly lower values in the foot than in the hand. In all five studied from one to three hours after delivery the oxygen saturation of blood from the foot was significantly lower than in the hand, indicating the presence of a veno-arterial shunt to the lower part of the body. Three of the five infants studied from three hours to three days after birth showed lower blood oxygen-saturation values in the foot than in the hand. None of the four infants who were older than three days showed significant oxygen-saturation differences. One baby who had a significant 
difference at two hours which persisted at two days showed no difference between hand and foot values by the fifth day. Should these studies be confirmed, then exchange transfusion is being carried out at a time when the ductus may be open functionally and when it may be the site of a venoarterial shunt.

From this it is but a step to the fact that the increase in pressure in the right side of the heart which may occur during exchange transfusion may increase the right-to-left shunt through the ductus and give rise to visible cyanosis in the distal half of the body. The increased pressure might be the result of a weakened myocardium going into failure, of excessively rapid transfusion or of partial spasm of the great abdominal veins which would act normally as a blood reservoir. Such an explanation is not entirely satisfactory, however. If the cyanosis were the result of a veno-arterial shunt through the ductus, it is surprising that it appeared in the very early stages of operation, that it did not become progressively more noticeable and that it resolved although operation was continued. Perhaps the withdrawal of the catheter for a few centimetres was responsible, as the blood flow which had been directed through the ductus venosus to the vena cava close to the heart would then be subjected to the cushioning effect of the portal circulation. Even if this were so, a major difficulty still remains. There was no doubt that the superficial veins over the front of the abdomen became much more obvious and that they drained upward over the chest. They did not constitute convincing evidence of occlusion of the inferior vena cava, but they suggested it. Catheterization of the umbilical vein takes the catheter tip to the inferior vena cava at $12-14 \mathrm{~cm}$. from the abdominal wall (van Loghem et al., 1949). When obstruction is encountered at $10-11 \mathrm{~cm}$., the catheter may have turned into the portal circulation and the withdrawal of blood may be very difficult or even impossible. Catheterization of the ductus venosus is not easy, but from a knowledge of the length of polythene tube introduced into these two infants the catheter tips must have lain in the ductus venosus or in the portal circulation. 'The fact that veins are capable of constriction may be observed by anyone who attempts to insert a cannula into one without due care' (McDowall, 1938). The ductus venosus is a foetal vessel which is in process of establishing or maintaining functional closure at the time when an exchange transfusion is being carried out. Irritation by a catheter could be expected to intensify the muscular constriction. The vessel is relatively short and it enters the inferior vena cava.
As a possible explanation for a very curious phenomenon it is suggested that spasm spreading to the greater vessel and producing partial occlusion merits consideration. Resolution of the physical signs might then follow partial withdrawal of the catheter and relaxation of the vena cava. Sphincter mechanisms exist on the great veins of some mammals. The dog has one on the hepatic vein, and the common seal has one on the posterior inferior vena cava (Harrison and Tomlinson, 1956). No reference can be found to the existence of any such structure in the human embryo at any point in development. Spasm of the inferior vena cava of animals may occur, however, as a reflex phenomenon in the absence of any recognizable sphincter. The fact that the vena cava of the horse could be made to constrict by stimulating the abdominal sympathetic was recorded by Valentin (1839). Splanchnic stimulation can cause constriction of the inferior vena cava (McDowall, 1938), and the portal vein can be made to constrict similarly (Burton-Opitz, 1913). Furthermore, Neil (quoted by McDowall, 1956) has obtained records of post-ganglionic sympathetic activity in fibres supplying the superior and inferior venae cavae. Such impulse discharge is markedly increased reflexly by such a remote procedure as the perfusion of the carotid-body areas with blood of low oxygen saturation. With spasm of the vena cava in mind, radiological studies employing a contrast medium were planned for such further cases as might be encountered, but none has occurred.

Even if both these explanations should be incorrect, the phenomenon, of which there may be milder unobserved degrees, reminds the paediatrician that he is producing acute dynamic changes in a circulatory system which is undergoing simultaneous adaptation to extra-uterine life. Following the occurrence of the second case the catheter tip has never been inserted for more than $7-8 \mathrm{~cm}$. from the abdominal wall. The employment of less rigid catheter material may have some advantage (Tizard, 1957).

Speed of Exchange. The development of signs of cardiac failure during exchange transfusion is not uncommon, but, apart from the unknown importance of the coexisting hyperpotassaemia and reduced calcium ion in Case $I$, the other biochemical findings in the series were unassociated with cardiac failure. The mechanical stress of exchange transfusion must be considerable. When a $7 \mathrm{lb}$. baby receives an $80 \mathrm{ml}$. per $\mathrm{lb}$. body weight exchange he is subjected to a constant withdrawal and replacement of from $3 \%$ to $7 \%$ of his blood volume every 
two to three minutes for $1 \frac{1}{2}$ to 2 hours. This takes place in a subject whose myocardium may be unhealthy before operation is begun and who may have other weak points in the circulatory system. The spleen, for example, may rupture either spontaneously or during exchange transfusion. In 1949 an exchange transfusion by the umbilical route was carried out by one of us (J. W. F.) on a severely affected baby of $5 \mathrm{lb}$. weight. Twenty-ml. aliquots of blood were used and all seemed well until $380 \mathrm{ml}$. had been exchanged. The infant then collapsed suddenly and died in a few moments. The catheter was clamped in situ, and at necropsy its tip was found in the inferior vena cava near the right atrium. The right side of the heart was extremely dilated. No other abnormality was found and the death may be attributed to the author's inexperience.

The deterioration observed so commonly by Walker and Neligan (1955) was thought to be unrelated to the initial condition of the infants, the birth weight, technical difficulties encountered or the rate of exchange. Yet at least one of their subjects was so delicately balanced that the injection of only $10 \mathrm{ml}$. at one point in an exchange transfusion dramatically converted an apparently well baby into a dead one. The effect of the too-rapid transfusion of anaemic patients was described by Starling (1918) as being like an overloaded heart-lung preparation. Venous pressure rises and cardiac output falls. Referring to what Wiener (1943) has described as 'speed shock', the British Medical Journal (1955) points out that the circulatory collapse is related, not to the properties of the stored blood, but to the total volume given and the speed of administration. The ability of children to tolerate relatively faster transfusion than adults was mentioned by Andrews and Coleman (1957), but their subjects were aged 4 years or more.

The need for care and experience in carrying out exchange transfusion has been stressed by Philipsborn et al. (1956). They found from the literature that most exchange transfusions were carried out in from one to two hours, and decided to investigate the effect of rapid exchange transfusion in pups. The operation was carried out on healthy mongrel pups through the femoral artery and employing their own heparinized blood. They discovered that much larger aliquots of blood could be used with safety than had been anticipated, and that the vascular trees of puppies could be expanded or contracted by as much as $25 \%$ without significantly altering the venous or arterial pressures or provoking changes in the ECG.

Circulatory equilibrium could be maintained under challenges far exceeding those which ordinarily occur during exchange transfusion. When two of the puppies were subjected to additional stress (barbiturate overdosage in one and exsanguination shock in another), however, they were less able to face the challenge of rapid exchange transfusion. There are obvious differences between the animal experiment and the human operation. The experiment employed healthy puppies receiving their own warm heparinized blood by the femoral artery, whereas the operation is carried out on human infants who have been the victims of a pathological process for some weeks and possibly involving the circulatory system, and who receive cool or cold stored citrated blood by the portal circulation.

Whatever the part played by excessive speed in the production of symptoms during exchange transfusion, the surgical principle of gentleness in operating is likely to be less upsetting to an infant than haste and undue manipulation. Where signs of distress appear they frequently subside if the baby is left undisturbed for five or ten minutes, and if cardiac failure is definitely present a small venesection may be carried out with advantage. Clinical deterioration may take place, however, in the absence of the classical signs of cardiac failure. The descriptive term 'shock' has been applied here to those infants who become cold, pale and limp, who develop varying degrees of abdominal distension and whose breathing may be accompanied in expiration by a faintly audible, murmuring whine. The pallor may be so striking that intraperitoneal haemorrhage is suspected. The condition was recognized by Walker and Neligan (1955), who also described it as shock and who recommended the giving of more blood as treatment. In the present investigation the clinical disturbance was unaccompanied by a single biochemical pattern.

Increasing Blood Viscosity. Variation in the viscosity of the blood influences the load carried by the heart (Whitby and Britton, 1953). Any increase in blood viscosity is naturally harmful when it increases the work thrown on a heart with reserves of strength seriously diminished by disease (Lancet, 1942). The immediate cause of death from haemolytic disease within 12 to 24 hours of birth is cardiac failure, for which the best immediate treatment is venesection and oxygen administration (Mollison, 1956). The viscosity of blood increases with increase in the haematocrit. For these reasons the wisdom of using packed or sedimented red cells for exchange transfusions may be doubted where the infant's original haematocrit is low and the haematocrit of the donor blood is appreciably higher. The transfusion of anaemic patients was found by Evans (1942) not to increase 
whole-blood viscosity, but he transfused with whole blood and the procedure was not comparable in volume or speed with exchange transfusion. No observations on changes in blood viscosity during exchange transfusions with whole blood and with sedimented cells have been found. If the viscosity does in fact rise with a rising haematocrit, then this would provide an objection to the routine exchange of the profoundly anaemic patient's blood with aliquots of sedimented cells. It is acknowledged, however, that if high-output cardiac failure is to be avoided in such infants the haemoglobin value may need to be raised to some extent. This may be done without employing sedimented cells for the whole operation, and it should be done slowly. Any residual anaemia may be corrected later by scalpvein transfusion when the patient's immediate survival has been assured. At the Simpson Memorial Maternity Pavilion emphasis has always been placed upon leisurely exchange with whole blood and upon the judicious maintenance of a negative balance between withdrawal and replacement in severely affected babies. Rising blood viscosity would be unlikely to bear any relationship to the clinical disturbance of mildly affected infants during exchange transfusion. The blood viscosity of such cases may in fact fall during operation.

In practice, however, there is probably less difference than might be thought between the blood from which the supernatant plasma has been decanted and whole blood which is allowed to stand undisturbed throughout the operation. Recent observations on blood containers in Edinburgh (Cumming, 1957) have shown how very difficult it is to maintain anything like an even suspension of cells in the standard glass transfusion bottles even when these are intermittently inverted.

\section{Cooling}

Chilling of the baby during exchange transfusion has been thought to be responsible for some of the abnormalities observed. The rectal temperatures of infants receiving blood at $70^{\circ}-80^{\circ} \mathrm{F}$. have been shown to fall from $97^{\circ}-99^{\circ}$ to $94^{\circ}-96^{\circ}$ in 21 cases studied by Marting et al. (1955). Cooling of this degree might occur in newborn infants exposed on a table for two hours unless careful precautions such as those described by Corey et al. (1955) are taken to avoid it. Four of the 21 infants, however, showed signs of shock after about $250 \mathrm{ml}$. had been exchanged. Their blood was noted to be poorly oxygenated, and this was attributed to hypothermia. Two of the four babies died. As a result of their investigation Marting et al. produced a glass helix which was immersed in a thermostatic- ally controlled water-bath and through which the donor blood was heated briefly on its way to the baby. The blood reached the infant at a temperature of $96^{\circ}-100^{\circ} \mathrm{F}$. Following this innovation the rectal temperatures of further infants studied were maintained, and their condition was claimed to be better than that of the infants who had received cool blood.

A dramatic description of cardiac arrest during exchange transfusion was given by Pew (1955). An infant with moderately severe haemolytic disease received an umbilical exchange transfusion with very fresh citrated blood. Shortly after $350 \mathrm{ml}$. had been exchanged the heart stopped suddenly. The infant's chest was opened and the heart massaged. Normal cardiac rhythm was restored after about two minutes. The exchange transfusion was continued and the exposed heart kept under observation. As blood was injected the heart was noted to slow and to be 'definitely cool'; indeed the bradycardia became so profound that further cardiac massage and the intracardiac injection of adrenaline were required. Normal rhythm was again restored; the exchange transfusion was carefully completed and the chest repaired. The total serum calcium concentration shortly after cardiac arrest was only $5.7 \mathrm{mg}$. per $100 \mathrm{ml}$. The baby showed some twitching when convalescent. The calcium was not recorded, but the sign disappeared when calcium gluconate was given. No information was provided about the speed of operation or where the tip of the catheter lay. Cooling was considered to be the possible precipitating factor. The first bottle of blood had been adequately warmed, and the crisis developed soon after the second, unwarmed, bottle had been brought into use.

The local application of cold to the front of the chest produces a slow heart rate, diminished systolic output and increased blood pressure (McDowall, 1956). Extracorporeal cooling of dogs down to temperatures of $26^{\circ} \mathrm{C}$. will not precipitate cardiac arrest, but the injection of very cold blood close to the heart can provoke auricular fibrillation (Delorme 1957). This would be particularly dangerous if it occurred in an infant with a devitalized myocardium and whose heart was receiving rapidly recurring influxes of 10-20 ml. of blood under pressure.

\section{Autonomic Stress}

The catheterization of the umbilical vein and the shunting to and fro of blood in the portal circulation may be more disturbing than has been thought previously. Walker and Neligan (1955) gained the impression that excessive traction on the umbilical cord during manipulation of the catheter produced vomiting. There is no doubt that the prodding of 
obstructions within the portal circulation makes the baby retch and he commonly regurgitates. Distension of the portal circulation by rapid transfusion may also precipitate this trouble. Such reflex stimulation was undoubtedly the cause of retching in this small series. Operations in the upper abdomen in relation to diaphragm and peritoneum may provoke hiccup, vomiting and shock. Exchange transfusion evokes dynamic changes in a region richly supplied with both afferent and efferent autonomic nerves and may be expected to give rise to some disturbance.

\section{Inexperience}

The experience of those conducting exchange transfusions varies widely. There is more to the procedure than exchanging $10 \mathrm{ml}$. aliquots of blood. In a surgical team it is unlikely that an operation carrying a comparable mortality would always be left to the house-surgeon or an inexperienced registrar. Yet junior staff may be left unsupervised to carry out an exchange transfusion in the belief sometimes held by senior staff inexperienced in this procedure that normal skill and common sense are all that is required. The apprenticeship to be served by the would-be operator of exchange transfusion is neither short nor easy, and even after many successes the experienced may be humbled by failure. It is interesting to note that Walker and Neligan (1955) had a low mortality, and yet Walker (1955) in a personal communication stated that, taking the country as a whole, the problem of unexpected death was more common than he had previously thought. This suggests that where both skill and experience were available the mortality was lower than in other areas where experience was less. Precisely this view has been expressed by Walker and Mollison (1957). They have shown from national figures that an appreciable number of infants dying of haemolytic disease had received exchange transfusions which were inadequate in volume, and that the actual number of deaths from haemolytic disease in England and Wales was in excess of the estimated annual mortality. Walker and Mollison (1957) calculated that some hospitals might be conducting an exchange transfusion as infrequently as once in four or five months. In such circumstances experience and team-work are hard to obtain. As many as $\mathbf{1 5 0}$ more affected infants might be saved annually if they were to receive exchange transfusion from experienced operators. We also believe that both the morbidity and mortality associated with exchange transfusion may be reduced by experience, and that the latter can be achieved best by centralizing treatment. Smaller obstetric or paediatric units might therefore have to sacrifice their occasional opportunities of carrying out the procedure, but many would be prepared to do so for the sake of the child. In the towns around Edinburgh a number of hospitals make a practice of sending the affected mother to the Simpson Memorial Maternity Pavilion for delivery, and for treatment of the child should that be necessary. By doing so they assure the infants of very early treatment by a team which possesses reasonable experience.

\section{Conclusions}

Various clinical disturbances may be observed during exchange transfusion in the infant suffering from haemolytic disease. Exchange transfusion produces considerable change in the patients' plasma electrolytes. The citrate level increases, potassium frequently increases and the calcium-ion level falls irrespective of the total serum calcium. The changes in serum electrolytes were shared by infants who were disturbed and by those who showed no abnormality. The depression of calcium ion can be neither prevented nor corrected by injecting calcium gluconate in the dose employed in this study. Other possible causes of clinical disturbance have been suggested. Evidence for them has not been sought in this study. They include such factors as interference with the circulation during the period of post-natal readjustment, excessive speed of exchange, changing blood viscosity, manipulation of the catheter within the abdomen, the injection of cool blood and, above all, inexperience on the part of the operator.

We wish to express our thanks to Professor R. W. B. Ellis and Dr. C. P. Stewart for their encouragement during this work, and to the former for his constructive criticism of the paper. We are grateful also to those registrars who took samples of blood and kept careful clinical records during some of the exchange transfusions.

The biochemical data included in this paper formed part of the Ph.D. thesis submitted successfully by H. S. to the University of Edinburgh.

\section{REFERENCES}

Ames, R., Syllm, I. and Rapoport, S. (1950). Pediatrics, 6, 361.

Andrews, L. G. and Coleman, D. J. (1957). Brit. med. J., 1, 19.

Born, G. V. R., Dawes, G. S., Mott, J. C. and Rennick, B. R. (1956). J. Physiol. (Lond.), 132, 304.

British Medical Journal (1955), 2, 1493.

Bunker, J. P., Stetson, J. B., Coe, R. C., Grillo, H. C. and Murphy, A. J. J. (1955). J Amer. med. Ass., 157, 1361.

Burton-Opitz, R. (1913). Quart. J. exp. Physiol., 7, 57.

Campbell, W. A. B. (1955). Arch. Dis. Childh., 30. 513.

Corey, E. L., Wood, J. B., Donegan, C. C. and Birdsong, M. (1955). J. Pediat., 47, 216.

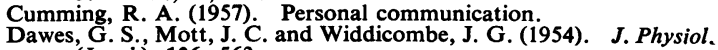
(Lond.), 126, 563 .

De Gowin, E. L., Harris, J. E. and Plass, E. D. (1940). J. Amer. med. Ass., 114, 850, 855 .

Delorme, E. J. (1957). Personal communication.

Eichelberger, L. (1941). J. biol. Chem., 138, 583.

Eldridge, F. L., Hultgren, H. N. and Wigmore, M. E. (1954). Science, 119,731 . 
Engel, F. L., Martin, S. P. and Taylor, H. (1949). Bull. Johns Hopk Hosp., 84, 285

Evans, P. (1942). Lancet, 1, 162.

Farquhar, J. W. and Lewis, I. C. (1949). Ibid., 1, 953.

Fenn, W. O. (1939). J. biol. Chem., 128, 297.

Govan, C. D. and Weiseth, W. M.'(1946). J. Pediat., 28, 550.

Guest, G. M. (1952). Amer. J. Dis. Child., 84, 638.

Harrison, R. J. and Tomlinson, J. D. W. (1956). Proc. zool. Soc. Lond., 126, 205.

Herlitz, G. (1942). Acta paediat. (Uppsala), 30, 153

Hill, F. S. (1954). Practical Fluid Therapy in Pediatrics. Philadelphia.

Houssay, B. A., Marenzi, A. D. and Gerschman, R. (1936). Rev. Soc. argent. Biol., 12, 434 ; ref. quoted by Fenn : Houssay B. A. and Marenzi, A. D., Rev. Soc. argent. Biol., 13, 139 (1937).

Joseph, M., Cohn, W. E. and Greenberg. D. M. (1939). J. biol. Chem 128,673.

King, E. J. (1951). Micro-analysis in Medical Biochemistry, 2nd ed. p. 45 . London.

Lancet (1942), 1, 176.

Lansing, A. I. and Scott, G. H. (1942). Anat. Rec., 84, 91.

Levine, H. D., Vazifdar, J. P., Lown, B. and Merrill, J. P. (1952) Amer. Heart J., 43, 437 .

Loghem, J. J. van, Bolhuis, J. H. van, Soeters, J. M. and Veeneklaas, G. M. H. (1949). Brit. med. J., 2, 49.

Mårtensson, J. (1940). Acta physiol. scand., 1, Suppl. 2, p. 59.

Marting, F. L. Wagoner, S. C. and Wilson, V. C. (1955). Amer. J. Dis. Child., 89, 289

McDowall, R. J.'S. (1938). The Control of the Circulation of the Blood. London.

(1956). Ibid. Supplemental Volume.

McLean, F. C. and Hastings, A. B. (1935), J. Biol. Chem., 108, 285.

Melrose, D. G., Dreyer, B., Bentall, H. H. and Baker, J. B. E. (1955) Lancet, 2, 21.
Miller, G., McCoord, A. B., Joos, H. A. and Clausen, S. W. (1954). Pediatrics, 13, 412 .

Mollison, P. L. (1951). Blood Transfusion in Clinical Medicine. Oxford.

- (1956). Ibid., 2nd ed. Oxford. - (1957). Annual Meeting British Paediatric Association (to be

Mudge, G. H. and Vislocky, K. (1949). J. clin. Invest., 28, 482

Nakasone, N., Watkins, E., Janeway, C. A. and Gross, R. E. (1954). J. Lab. clin. Med., $43,184$.

Natelson, S., Pincus, J. B. and Lugovoy, J. K. (1948). J. clin. Invest.,

Pew, W. L. (1955). J. Pediat., 47, 645

Philipsborn, H. F., Miller, R. A. and Traisman, H. S. (1956). Ibid., 49, 67.

Sobel, A.E. and Sobel, B. A. (1939). J. biol. Chem., 129, 721

Starling. E. H. (1918). The Linacre Lecture on the Law of the Heart. London.

Tarail, R. and Elkinton, J. R. (1949). J. clin. Invest., 28, 99.

Thunberg, T. (1953) Physiol. Rev., 33,

Tizard, J. P. M. (1957). Personal communication.

Valentin, G. (1839). De functionibus nervorum cerebralium et nervi sympathici. Huber, Berne.

Walker, W. (1955). Personal communication.

- (1956). Personal communication and Mollison, P. L. (1957). Lancet, 1, 1309.

- and Neligan, G. A. (1955). Brit. med. J., 1, 681.

Wexler, I. B., Pincus, J. B., Nateison, S. and Lugovoy, J. K. (1949). J. clin. Invest., $28,474$.

Whitby, L. E. H. and Britton, C. J. C. (1953). Disorders of the Blood. 7 th ed. London.

Wiener, A. S. (1943). Blood Groups and Transfusion. 3rd. ed. Springfield (Illinois).

Winkler, A. W., Hoff, H. E. and Smith, P. K. (1939). Amer. J. Physiol., 127, 430. 